\title{
TEKNOLOGI KONSERVASI ARTIFICIAL TEMPLE REEF SEBAGAI PENGENDALI ABRASI PESISIR PULAU TABUHAN DESA BANGSRING KECAMATAN WONGSOREJO BANYUWANGI
}

\author{
Zulis Erwanto ${ }^{1}$, Umi Masluha ${ }^{2}$ \\ Politeknik Negeri Banyuwangi \\ Jl. Raya Jember Km. 13, Labanasem, Kabat, Banyuwangi \\ ${ }^{1}$ zulis.erwanto@poliwangi.ac.id \\ 2umimasluha0305@gmail.com
}

\begin{abstract}
Abstrak
Pantai Bangsring memiliki ekosistem terumbu karang yang berkaitan erat dengan kondisi kehidupan masyarakat nelayan ikan hias dan menggantungkan hidupnya pada keberadaan ekosistem terumbu karang. Beberapa permasalahan yaitu kurangnya pengelolaan vegetasi dan rusaknya terumbu karang di Pesisir Pulau Tabuhan. Demi menyelamatkan dan memelihara terumbu karang sebagai tempat perkembangbiakan ikan dan sebagai pelindung pulau dari abrasi dan erosi laut, maka dibuatlah Artificial Temple Reef berbahan abu ampas tebu yang ramah lingkungan yang akan diletakkan di Pesisir Pulau Tabuhan.

Tahapan kegiatan dimulai dari survey lokasi, sosialisasi program kerja, penyuluhan konservasi biota laut, pelatihan pembuatan produk Artificial Temple Reef, Konservasi Vegetatif, Penenggelaman Artificial Temple Reef, dan Publikasi. Artificial Temple Reef merupakan inovasi produk terumbu karang buatan dengan model kerangkeng berduri dan berbentuk model candi berongga dari bahan campuran semen, pasir dan abu ampas tebu yang ramah lingkungan.

Untuk menerapkan konservasi biota laut dilakukan dengan pelatihan pembuatan Artificial Temple Reef guna meningkatkan keterampilan kelompok nelayan dan partisipasi kelompok nelayan dalam melakukan penenggelaman Artificial Temple Reef di Pulau Tabuhan dan Pesisir Bangsring. Komposisi mix desain Artificial Temple Reef dengan perbandingan 1 Abu Ampas Tebu : 2 Pc : 3 Ps. Teknik pengelolaan dan perlindungan biota laut dilaksanakan melalui program penyuluhan konservasi biota laut guna meningkatkan kesadaran, perubahan sikap dan perilaku kelompok nelayan, juga melakukan konservasi vegetatif, serta pencangkokan cemara udang untuk program keberlanjutan. Jumlah kelompok sasaran 209 anggota dari Kelompok nelayan Samudera Bakti dan Kelompok nelayan Bangsring Underwater. Dengan diserahterimakan cetakan Artificial Temple Reef diharapkan program bisa dikembangkan dan dilanjutkan oleh Kelompok Nelayan secara swadaya dan produktif, sehingga konservasi biota laut tetap berjalan.
\end{abstract}

Keywords-Artificial Temple Reef, Biota Laut, Konservasi, Pulau Tabuhan

\section{PENDAHULUAN}

Pantai Bangsring adalah kawasan perairan yang berada di ujung timur Pulau Jawa, tepatnya berada di Desa Bangsring, Kecamatan Wongsorejo, Kabupaten Banyuwangi. Pantai Bangsring memiliki ekosistem terumbu karang yang berkaitan erat dengan kondisi kehidupan masyarakat yang berada di sekitar kawasan ini, dimana masyarakat di sekitar Pantai Bangsring kebanyakan adalah nelayan ikan hias dan menggantungkan hidupnya pada keberadaan ekosistem terumbu karang yang ada di kawasan tersebut. Ditambah lagi, kawasan ini juga dibuka secara umum sebagai kawasan ekowisata bahari sejak bulan Agustus 2014 termasuk destinasi Pulau Tabuhan yang menjadi wisata pulau di Desa Bangsring.

Uniknya nelayan Bangsring mampu mengemas area konservasi menjadi destinasi wisata yang ramai Pengelola Bunder (Bangsring Underwater), Bapak Sukirno menuturkan dulunya perairan Bangsring menjadi lokasi penangkapan ikan dengan menggunakan bom ikan jenis potassium sianida. Penggunaan potassium ini dilakukan baik oleh nelayan yang menangkap ikan konsumsi maupun ikan hias. Cara ini membuat ekosistem dibawah laut Bangsring seperti terumbu karang rusak parah, yang akhirnya menurunkan populasi ikan secara drastis.

Mulai dari memberikan sosialisasi dan edukasi di setiap perkumpulan nelayan, yang juga diikuti pengepul ikan. Selain membangun mind set, secara kelembagaan kelompok nelayan juga memfasilitasi pengurusan perijinan kapal bagi nelayan yang mau merubah cara penangkapan ikannya. Upaya transplantasi juga dilakukan untuk percepatan pemulihan. Besarnya manfaat yang dirasakan nelayan ini membuat mereka juga sadar untuk mengembangkan area konservasi. Di area ini nelayan dilarang melakukan aktivitas penangkapan ikan baik menjaring maupun memancing. Keterlibatan nelayan mulai dari menyewakan kapal, mengelola atraksi wisata, sampai guide untuk snorkling dan diving sampai menyewakan rumah mereka untuk homestay.

Nelayan Desa Bangsring, bersama dengan lembaga swadaya masyarakat pemerhati lingkungan, mencoba menyelamatkan kawasan terumbu karang tersebut. Langkahnya dilakukan dengan 
memperbaiki ekosistem laut yang rusak melalui penanaman bibit terumbu karang. Kegiatan kelompok nelayan ini diharapkan terus tumbuh kesadarannya. Mulai dari penanaman vegetasi pantai, transpalantasi terumbu karang, pengawasan aktivitas nelayan juga dilakukan untuk menjaga laut dari kerusakan. Oleh karena itu, perlu adanya kegiatan bina desa di Desa Bangsring untuk konservasi biota laut dengan teknologi Artificial Temple Reef, yang dibuat dari bahan campuran abu ampas tebu yang ramah lingkungan dengan cara membuat terumbu karang buatan berbentuk candi yang akan diletakkan di Pesisir Pulau Tabuhan sebagai salah satu bentuk partisipasi dan pemerhati konservasi laut untuk menyelamatkan dan memelihara terumbu karang sebagai tempat perkembangbiakan ikan dan memelihara keanekaragaman hayati biota laut. Juga sebagai pelindung pulau dari abrasi dan erosi laut.

\section{TARGET DAN LUARAN}

Dari berbagai masalah yang dihadapi oleh kelompok nelayan tersebut maka solusi yang ditawarkan adalah pembuatan produk Artificial Temple Reef yang berbentuk candi dengan bahan campuran dari limbah abu ampas tebu, semen dan pasir yang ramah lingkungan dan juga berbentuk model kerangkeng berduri sebagai bentuk konservasi biota laut dan pelindung pantai dari abrasi dan erosi gelombang laut. Oleh sebab itu sesuai dengan prioritas kebutuhan maka ditawarkan solusi terhadap permasalahan yang dihadapi kelompok nelayan yakni dengan penyuluhan konservasi biota laut, pelatihan pembuatan produk Artificial Temple Reef, dan Penenggelaman Artificial Temple Reef. Untuk keberlanjutan kegiatan ini melakukan konservasi vegetatif dan pencangkokan cemara udang.

Tabel I. Target Capaian Luaran

\begin{tabular}{|c|l|l|}
\hline No & \multicolumn{1}{|c|}{ Jenis Luaran } & \multicolumn{1}{|c|}{$\begin{array}{c}\text { Indikator } \\
\text { Capaian }\end{array}$} \\
\hline 1 & Publikasi ilmiah di jurnal/prosiding & Draft \\
\hline 2 & $\begin{array}{l}\text { Publikasi pada media massa } \\
\text { (cetak/elektronik) }\end{array}$ & Sudah terbit \\
\hline 3 & $\begin{array}{l}\text { Peningkatan omzet pada mitra yang } \\
\text { bergerak dalam bidang ekonomi }\end{array}$ & Tidak ada \\
\hline 4 & $\begin{array}{l}\text { Peningkatan kuantitas dan kualitas } \\
\text { produk }\end{array}$ & Ada \\
\hline 5 & $\begin{array}{l}\text { Peningkatan pemahaman dan } \\
\text { keterampilan masyarakat }\end{array}$ & Ada \\
\hline 6 & $\begin{array}{l}\text { Peningkatan ketentraman/kesehatan } \\
\text { masyarakat (mitra masyarakat umum) }\end{array}$ & Tidak ada \\
\hline 7 & $\begin{array}{l}\text { Jasa, model, rekayasa sosial, sistem, } \\
\text { produk/barang }\end{array}$ & Produk \\
\hline 8 & $\begin{array}{l}\text { Hak kekayaan intelektual (paten, paten } \\
\text { sederhana, hak cipta, merek dagang, } \\
\text { rahasia dagang, desain produk industri, } \\
\text { perlindungan varietas tanaman, } \\
\text { perlindungan topografi. }\end{array}$ & Tidak ada \\
\hline 9 & Buku Ajar & Tidak ada \\
\hline
\end{tabular}

Sumber : Hasil Analisis, 2018

\section{METODE PELAKSANAAN}

Dalam pelaksanaan program ini, metode pelaksanaan yang digunakan didasari dari permasalahan yang ada di Desa Pakel yaitu mengatasi permasalahan kebutuhan air bersih melalui proses pengolahan menggunakan filter beton pasir melalui beberapa tahapan yaitu:

a. Survey Lokasi dan Kondisi Pesisir Pulau Tabuhan.

b. Kegiatan Sosialisasi Program Kerja Bina Desa.

c. Kegiatan Penyuluhan Konservasi Biota Laut dan Terumbu Karang.

d. Pembuatan Cetakan Artificial Temple Reef dari Fiber.

e. Kegiatan Pelatihan Pembuatan Produk Artificial Temple Reef.

f. Konservasi Vegetatif Penanaman Bibit Cemara Udang dan Bibit Buah Naga.

g. Kegiatan Penenggelaman Produk Artificial Temple Reef di Pesisir Pulau Tabuhan dan di Pesisir Bangsring.

h. Monitoring dan Evaluasi Indikator Keberhasilan Program

i. Publikasi

j. Pelaporan Akhir

Kegiatan ini difokuskan pada proses pembuatan teknologi produk Artificial Temple Reef. Teknologi yang akan diterapkan adalah pembuatan produk inovasi Artificial Temple Reef berbahan abu ampas tebu, dimana terumbu karang tersebut dibuat dari campuran abu ampas tebu yang dibentuk menyerupai candi berongga dan berlubang di seluruh sisi-sisinya. Diusahakan permukaan terumbu karang buatan tersebut dibuat kasar dan tidak rata atau dibuat bergelombang, dengan maksud agar dari permukaan kasar tersebut sebagai tempat menempelnya plankton dan untuk menumbuhkan terumbu karang baru. Abu ampas tebu sendiri bahan alami yang ramah lingkungan yang dapat digunakan untuk campuran pembuatan terumbu karang buatan, untuk media dalam mempercepat proses melekatnya polip-polip karang. Model desain dapat dilihat pada Gambar I.

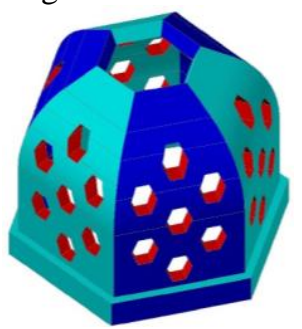

(a) Artificial Temple Reef Model

Candi Berbahan Abu Ampas Tebu

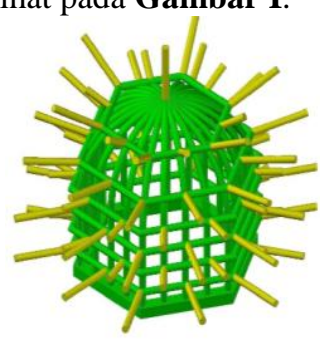

(b) Artificial Temple Reef Model Kerangkeng Berduri
Gambar I. Produk Inovasi Artificial Temple Reef (Hasil Desain, 2018) 


\section{KELAYAKAN PERGURUAN TINGGI}

Pusat Penelitian Dan Pengabdian Kepada Masyarakat Politeknik Negeri Banyuwangi khususnya telah berperan aktif dalam program hibah bina desa dan program desa binaan, antara lain :

1. Program Hibah Bina Desa Pengembangan Infrastruktur Pariwisata Air Terjun Selendang Arum Desa Sumber Arum Kecamatan Songgon, sumber dana Belmawa Ristekdikti tahun 2015.

2. Program Hibah Bina Desa Pengembangan Infrastruktur Pariwisata Air Terjun Telunjuk Raung Mangaran dan Pelatihan TIK Di Desa Sumber Arum Kecamatan Songgon Kabupaten Banyuwangi, sumber dana Belmawa Ristekdikti tahun 2016.

3. Program Hibah Bina Desa Konservasi Biota Laut Dengan Teknologi Artificial Temple Reef di Pesisir Pulau Tabuhan Desa Bangsring Kecamatan Wongsorejo Banyuwangi, sumber dana Belmawa Ristekdikti tahun 2018.

4. (Ompimpah) Optimalisasi Pengolahan Sampah Menjadi Paving di TPSA Bulusan Kabupaten Banyuwangi, sumber dana DIPA PNBP Politeknik Negeri Banyuwangi tahun 2018.

5. Desa Binaan Berbasis Ekonomi Pembangunan Tanam Sayuran Polybag Sebagai Pemberdayaan Masyarakat Terdampak Banjir di Desa Alasmalang Kecamatan Singojuruh Kabupaten Banyuwangi, sumber dana DIPA PNBP Politeknik Negeri Banyuwangi tahun 2018.

6. Pemberdayaan Masyarakat Dalam Memanfaatkan Limbah Kulit Kopi Menjadi Teh Cascara di Desa Gumuk Candi, Kecamatan Songgon, sumber dana DIPA PNBP Politeknik Negeri Banyuwangi tahun 2018.

7. Workshop Pengolahan Sumber Daya Mangrove Menjadi Produk Unggulan Masyarakat Guna Meningkatkan Ekowisata Teluk Pangpang Di Dusun Krajan Desa Wringin Putih Kecamatan Muncar Banyuwangi, sumber dana DIPA PNBP Politeknik Negeri Banyuwangi tahun 2018.

8. Desa Baca Cerdas Untuk Meningkatkan Kualitas Pendidikan Melalui Rumah Literasi dan Pembenahan Infrastruktur Pendidikan di Dusun Cinci, Kabupaten Banyuwangi, sumber dana DIPA PNBP Politeknik Negeri Banyuwangi tahun 2018.

\section{HASIL DAN LUARAN YANG DICAPAI}

Keindahan alam bawah laut Selat Bali di Bangsring Underwater, di Desa Bangsring Kecamatan Wongsorejo memang diakui menjadi destinasi wisata alam yang menyedot wisatawan domestik dan mancanegara. Bangsring Underwater dikenal destinasi wisata berbasis konservasi dengan perairan yang jernih dan terdapat terumbu karang alami dan buatan. Keanekaragaman sumber daya ikan di Pantai Bangsring menjadi daya tarik wisata tersendiri bagi wisatawan yang mengunjungi pantai ini. Pantai Bangsring memiliki ekosistem terumbu karang dengan kondisi yang cukup baik, dimana hasil monitoring bulan Januari 2015 menunjukkan penutupan karang hidup di Pantai Bangsring mencapai 38,33\% (30\% karang keras dan 8,33\% karang lunak). Pantai Bangsring juga kaya akan keanekaragaman jenis ikan karang, invertebrata laut, dan penyu. Disamping itu, Pantai Bangsring juga seringkali disinggahi oleh bermacam jenis burung laut. Selain keanekaragaman biotanya, Pantai Bangsring juga dikenal dengan pemandangan matahari terbitnya.

Pulau Tabuhan termasuk bagian kawasan pantai Bangsring yang merupakan kawasan konservasi terumbu karang yang memiliki status sebagai kawasan perlindungan laut (Marine Protected Area). Kawasan perlindungan laut di Pantai Bangsring ditetapkan melalui PERDES Bangsring No. 2 Tahun 2009 tentang Zona Perlindungan Bersama (ZPB). Kawasan ini memiliki zona inti seluas 1 ha pada koordinat $-8.052000^{\circ} \mathrm{N}$ dan $114.431722^{\circ} \mathrm{E}$ dengan zona pendukung seluas 12 ha yang berada disekitarnya, sehingga keseluruhan ZPB memiliki luas total sekitar 13 ha. Kawasan ZPB dibuka menjadi kawasan ekowisata sekitar bulan Agustus 2014 bersamaan dengan datangnya hibah berupa rumah apung dari Kementerian Kelautan dan Perikanan pada saat itu.

Nelayan Desa Bangsring, bersama dengan lembaga swadaya masyarakat pemerhati lingkungan mencoba menyelamatkan kawasan terumbu karang yang rusak seperti terlihat pada Gambar II. Langkahnya dilakukan saat ini dengan memperbaiki ekosistem laut yang rusak melalui penanaman bibit terumbu karang (transplantasi). Tapi hal ini dirasa kurang efektif karena pertumbuhan bibit terumbu karang sangat lambat dan membutuhkan waktu yang lama. Oleh karena hal tersebut, diperlukan terobosan dengan menerapkan teknologi inovasi Artificial Temple Reef atau inovasi terumbu karang buatan berbentuk candi. Hal ini dimaksudkan agar bisa melindungi biota laut untuk berkembangbiak dari serangan predator, serta sebagai media terumbu karang untuk tumbuh dan berkembang.

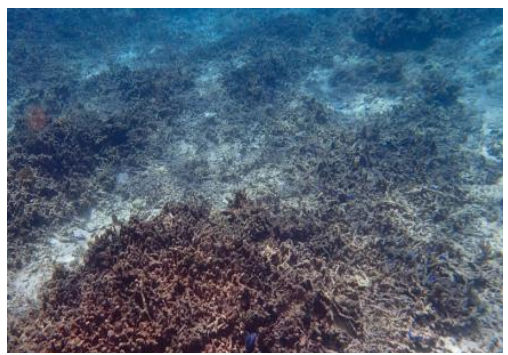

Gambar II. Kondisi Terumbu Karang Di Pesisir Laut Pulau Tabuhan Yang Mengalami Kerusakan (Dokumentasi, 2018) 
Perlu menumbuhkan kesadaran masyarakat Desa Bangsring dan Para Nelayan khususnya untuk memelihara pesisir dan lautan dari kerusakan terumbu karang dan penangkapan ikan dengan tidak merusak ekosistem laut. Kegiatan dan usaha lain di Pulau Tabuhan yaitu dengan cara pemulihan vegetasi Pantai Pulau Tabuhan, tetapi kegiatan tersebut akan terus dikembangkan bersama-sama para Nelayan, pemerhati, maupun Instansi terkait. Diharapkan kegiatan kelompok nelayan ini terus tumbuh kesadarannya. Mulai dari penanaman vegetasi pantai, transpalantasi terumbu karang, pengawasan aktivitas nelayan lain juga dilakukan untuk menjaga laut dari kerusakan.

Pantai Bangsring, Desa Bangsring, Kecamatan Wongsorejo, Kabupaten Banyuwangi Jawa Timur terletak di sekitar $8^{\circ} 4^{\prime} 10.29^{\prime \prime}$ Lintang Selatan dan $114^{\circ} 25^{\prime 2} 23.26^{\prime \prime}$ Bujur Timur. Lokasi pantai ini berada di Selat Bali dan berjarak sekitar $10 \mathrm{Km}$ utara Pelabuhan Ketapang. Lokasi pulau Tabuhan dari Institusi sejauh 36,7 Km. Untuk mencapai Pulau Tabuhan, dibutuhkan waktu tempuh sekitar satu jam dari kota Banyuwangi, 20 menit untuk menuju ke Pantai Bangsring, sementara 30 menit sisanya digunakan untuk mencapai Pulau Tabuhan dengan kapal wisata seperti pada Gambar III.

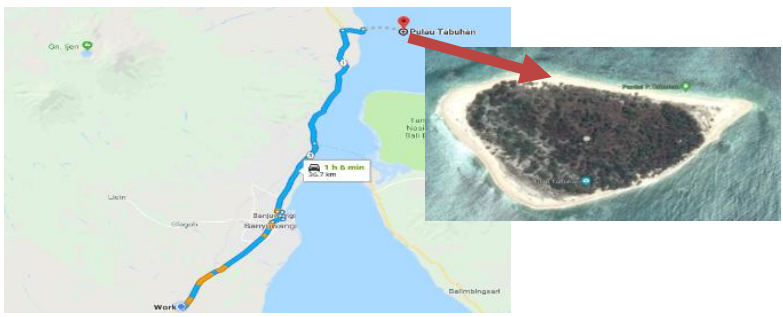

Gambar III. Lokasi Daerah Sasaran Pulau Tabuhan, Desa Brangsing, Kecamatan Wongsorejo, Kabupaten Banyuwangi (Google Map, 2018)

Pemberdayaan masyarakat dan tahapan kegiatan yang dilakukan antara lain :

1. Sosialisasi kegiatan Program Hibah Bina Desa tentang rencana program kerja di kelompok mitra dan kegiatan konservasi biota laut dengan teknologi Artificial Temple Reef berbahan abu ampas tebu yang ramah lingkungan untuk dijadikan bahan terumbu karang buatan yang berbentuk candi sebagai tempat perkembangbiakan dan perlindungan ikan serta pelestarian terumbu karang seperti terlihat pada Gambar IV.

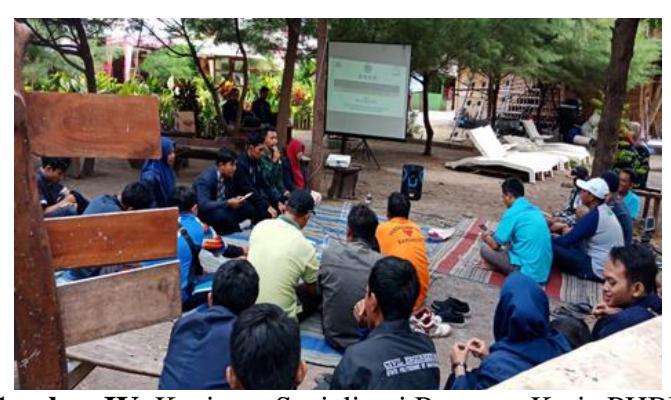

Gambar IV. Kegiatan Sosialisasi Program Kerja PHBD (Dok, 2018)

2. Pembuatan cetakan dan latihan pembuatan produk. Cetakan Artificial Temple Reef berbentuk candi dibuat dari bahan fiber agar bisa fleksibel yang terdiri dari dua model yaitu model candi segienam yang tinggi dan ada yang pendek. Lalu ada juga model Artificial Temple Reef model kerangkeng berduri yang dibuat dari besi tulangan yang diselimuti campuran abu ampas tebu, semen dan pasir. Begitu pula komposisi yang digunakan untuk membuat Artificial Temple Reef yang berbentuk candi seperti pada Gambar V.

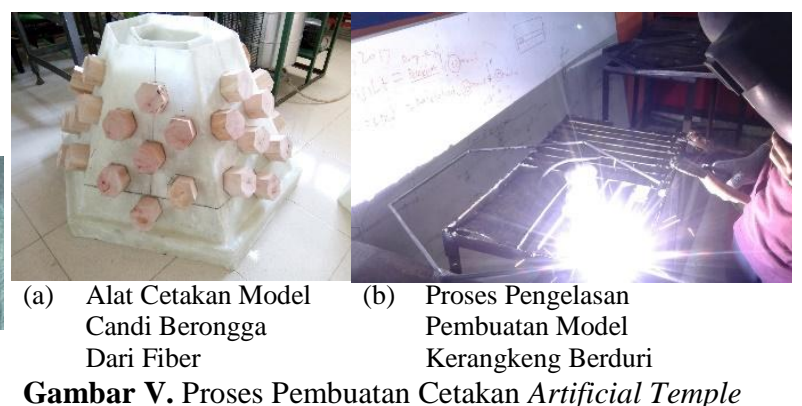
Reef (Dok, 2018)

Proses latihan pembuatan produk sebelum melakukan pelatihan ke kelompok nelayan dapat dilihat pada Gambar VI.

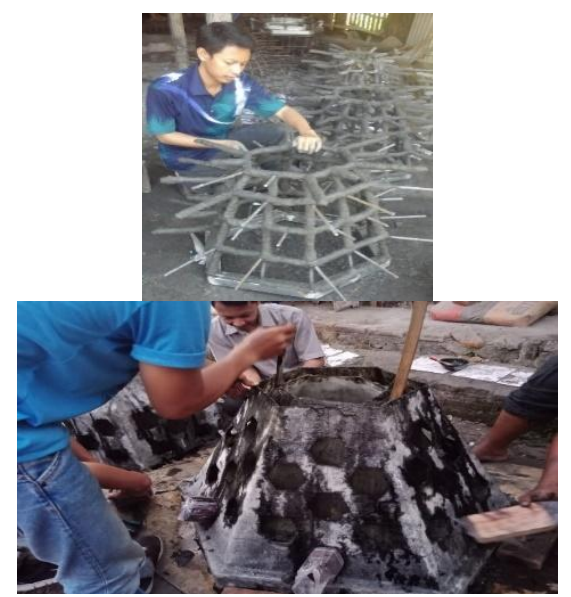

Gambar VI. Proses Latihan Pembuatan Produk Artificial Temple Reef Model Kerangkeng Berduri dan Model Candi Beton (Dok, 2018) 
3. Penyuluhan kepada para kelompok nelayan tentang konservasi biota laut dan terumbu karang dengan mendatangkan narasumber dari Universitas Hang Tuah Surabaya Ibu Dr. Nirmalasari Idha Wijaya, S.Pi., M.Si. dengan tujuan untuk meningkatkan kesadaran, perubahan sikap dan perilaku kelompok Nelayan akan pentingnya memelihara biota laut dan terumbu karang alami maupun buatan. Sesi foto bersama hasil kegiatan penyuluhan dapat dilihat pada Gambar VII.

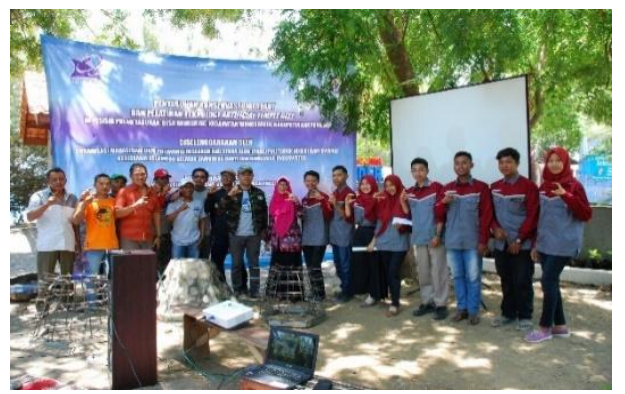

Gambar VII. Kegiatan Penyuluhan Konservasi Biota Laut dan Terumbu Karang (Dok, 2018)

4. Kegiatan pembuatan produk inovasi Artificial Temple Reef berbahan abu ampas tebu yang ramah lingkungan untuk dijadikan bahan campuran terumbu karang buatan yang berbentuk candi yang terdiri dari campuran abu ampas tebu, semen dan pasir. Kegiatan hasil pelatihan pembuatan produk ke kelompok Nelayan dapat dilihat pada Gambar VIII.

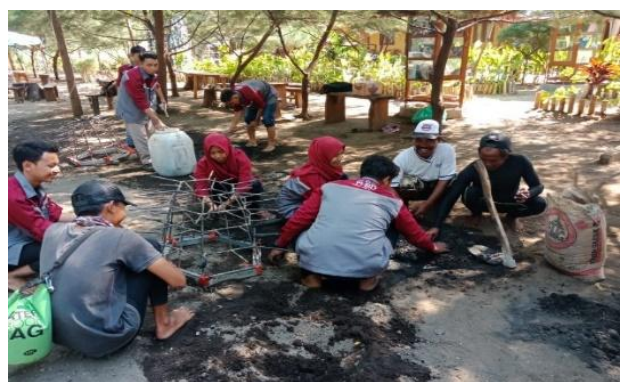

Gambar VIII. Pelatihan Pembuatan Produk Artificial

Temple Reef Bersama Kelompok Nelayan (Dok, 2018)

Tahapan pembuatan produk inovasi Artificial

Temple Reef:

a. Pembuatan bekisting atau cetakan sesuai dengan model Artificial Temple Reef dari fiber dan dari tulangan besi untuk dibentuk kerangkeng berduri.

b. Persiapan bahan antara lain semen, pasir, dan abu ampas tebu.

c. Mix design komposisi campuran pembuatan Artificial Temple Reef dengan komposisi 1 Abu Ampas Tebu : 2 Semen : 3 Pasir.

d. Pencetakan bahan ke dalam cetakan Artificial Temple Reef untuk model candi beton. Dan juga menyelimuti tulangan besi dengan bahan adonan beton tersebut untuk model kerangkeng berduri.

Produk Artificial Temple Reef dari hasil pelatihan ke kelompok nelayan dapat dilihat pada Gambar IX dan $X$.

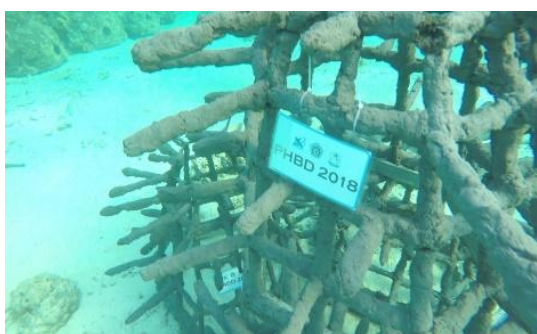

Gambar IX. Produk Artificial Temple Reef Model Kerangkeng Berduri Yang Sudah Ditenggelamkan ke Dasar Laut Pesisir Pulau Tabuhan (Dok, 2018)

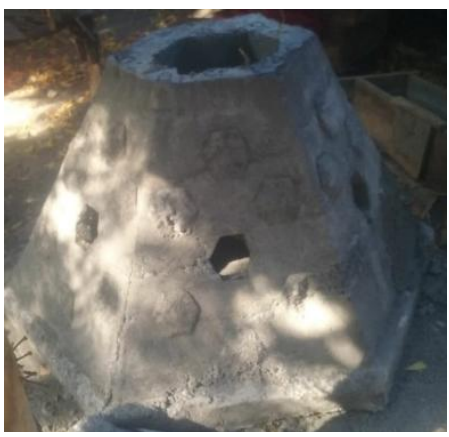

Gambar X. Produk Artificial Temple Reef Model Candi Berbahan Abu Ampas Tebu (Dok, 2018)

5. Kegiatan penanaman vegetasi cemara udang atau cemara laut untuk pemulihan vegetasi alami di Pulau Tabuhan. Juga menanam tanaman buah naga seperti pada Gambar XI.

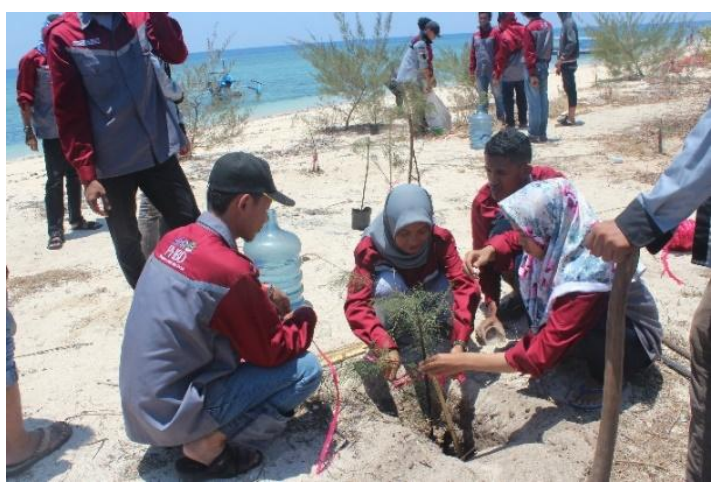

Gambar XI. Konservasi Vegetatif Penanaman Cemara Udang Di Pulau Tabuhan (Dok, 2018)

Untuk program keberlanjutan dilakukan program pencangkokan (Gambar XII) untuk dilakukan penanaman lebih lanjut di Pulau Tabuhan, karena dalam penanaman vegetasi terkendala faktor cuaca. Disarankan untuk penanaman lebih baik dilakukan saat musim penghujan, agar bibit tanaman bisa tumbuh dan berkembang. 


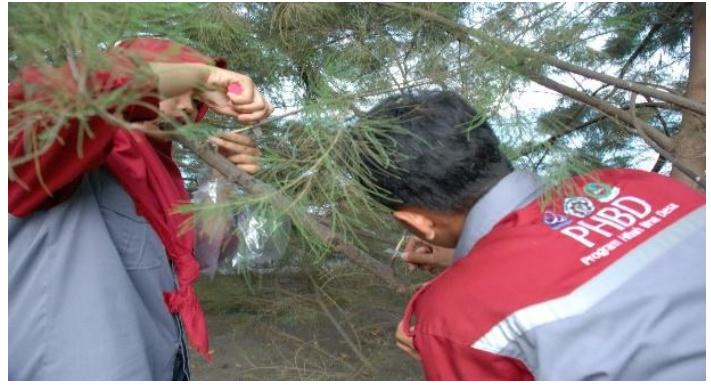

Gambar XII. Pencangkokan Cemara Udang (Dok, 2018)

6. Pelaksanaan penenggelaman Artificial Temple Reef pada titik-titik yang telah ditentukan sebelumnya dari hasil koordinasi dengan kelompok mitra di wilayah sekitar pesisir Pulau Tabuhan. dari hasil penelitian Fuad, M. Arif Zainul (2016), bahwa lokasi penempatan untuk terumbu karang buatan di Perairan Brangsing sebaiknya berada di kedalaman 10-30 meter berada pada jarak sekitar 100-200 meter dari garis pantai seperti terlihat pada Gambar XIII.

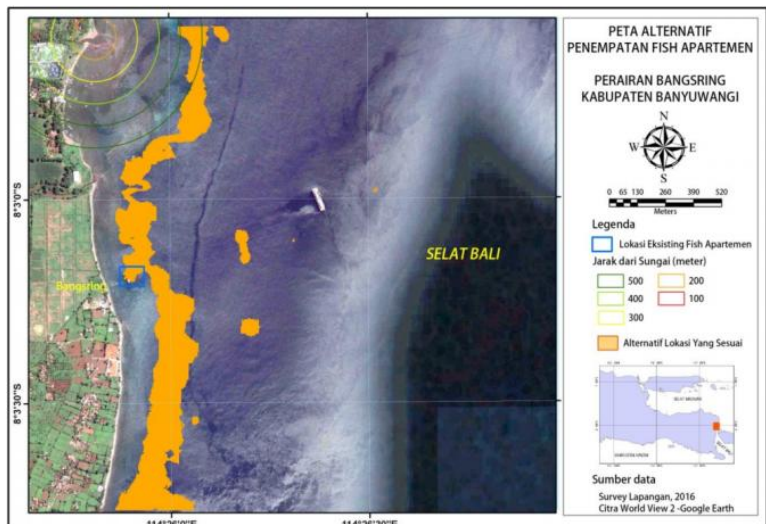

Gambar XIII. Peta Lokasi Rencana Penempatan Artificial Temple Reef (Fuad, 2016)

7. Publikasi dan promosi melalui media massa dan website, serta pembuatan poster dan pamflet. Publikasi ilmiah diterbitkan di Jurnal J-Dinamika Politeknik Negeri Jember dan publikasi media cetak Radar Banyuwangi serta Media Online Kompasiana.

Besarnya nilai manfaat wisata yang ada di Pantai Bangsring menunjukkan pentingnya keberadaan kegiatan tersebut ditengah keberagaman kegiatan yang ada disekitarnya. Hal ini dapat menjadi saran pengelolaan agar pengelola di Pantai Bangsring dapat tetap menjaga kelestarian sumber daya alam berupa terumbu karang pada kawasan tersebut untuk menunjang kegiatan wisata yang menjadi titik tumpu kegiatan ekonomi di kawasan tersebut. Van Beukering et al. (2007), menyatakan bahwa menurunnya kualitas sumberdaya terumbu karang akan berpengaruh negatif terhadap kegiatan wisata seperti snorkeling dan diving. Selain itu, terumbu karang merupakan aset ekonomi dan budaya yang berharga untuk masyarakat pesisir, sehingga bentuk pengelolaan berkelanjutan harus dilakukan untuk menjaga ekosistem tersebut agar tetap lestari.

Menurut Asadi (2017), total manfaat ekonomi (Total Economic Value) ekosistem terumbu karang di Pantai Bangsring dihitung dengan menjumlahkan nilai - nilai yang telah diuraikan sebelumnya. Nilai nilai tersebut berasal dari manfaat langsung, manfaat tidak langsung, manfaat pilihan, manfaat keberadaan, dan manfaat warisan. Berdasarkan hasil yang diperoleh, total manfaat ekonomi ekosistem terumbu karang di Pantai Bangsring adalah sebesar Rp. 38.206.318.845,- per tahun. Sumbangan terbesar berasal dari manfaat wisata sebesar $66 \%$, disusul oleh manfaat penangkapan ikan hias sebesar $16 \%$, manfaat keberadaan sebesar $10 \%$, dan manfaat warisan masing - masing sebesar $8 \%$.

\section{KESIMPULAN DAN SARAN}

1. Untuk menerapkan konservasi biota laut dengan teknologi Artificial Temple Reef di Pesisir Pulau Tabuhan Desa Bangsring Kecamatan Wongsorejo Banyuwangi sudah terlaksana dengan program pelatihan pembuatan Artificial Temple Reef guna meningkatkan keterampilan kelompok nelayan dan partisipasi kelompok nelayan dalam melakukan penenggelaman Artificial Temple Reef di Pulau Tabuhan dan Pesisir Bangsring.

2. Untuk mengetahui teknik pengelolaan dan perlindungan biota laut dengan konsep Artificial Temple Reef, sudah dilaksanakan melalui program penyuluhan konservasi biota laut guna meningkatkan kesadaran, perubahan sikap dan perilaku kelompok nelayan, juga melakukan konservasi vegetatif di Pulau Tabuhan, serta program pencangkokan cemara udang untuk program keberlanjutan.

3. Jumlah kelompok sasaran 209 anggota dari Kelompok nelayan Samudera Bakti dan Kelompok nelayan Bangsring Underwater.

4. Publikasi ilmiah diterbitkan di Jurnal J-Dinamika Politeknik Negeri Jember dan publikasi media cetak Radar Banyuwangi serta Media Online Kompasiana.

Beberapa saran dalam kegiatan konservasi biota laut dan pembuatan terumbu karang, antara lain:

1. Perlu modifikasi desain terumbu karang buatan dalam bentuk puzzle agar memudahkan akses pengangkutan terumbu karangnya menuju ke Pulau Tabuhan, sehingga penataannya dapat dilakukan di dasar laut.

2. Perlu diperhatikan faktor cuaca dan iklim karena sangat mempengaruhi kegiatan konservasi biota laut maupun konservasi vegetatif. 


\section{UCAPAN TERIMA KASIH}

Ucapan terima kasih kami sampaikan kepada

Direktorat Jenderal Pembelajaran dan
Kemahasiswaan, Kementerian Riset, Teknologi, Dan Pendidikan Tinggi atas pendanaan yang telah diberikan dalam Program Hibah Bina Desa Tahun 2018.

\section{DAFTAR PUSTAKA}

[1] Asadi, M.A and Andrimida, A. 2017. Economic Valuation Of Coral Reefs Ecosystem Of Bangsring, Banyuwangi, Indonesia. ECSOFiM: Economic and Social of Fisheries and Marine Journal. Vol 4 (2): 144 -152, e-ISSN:25285939, Permalink/DOI: http://dx.doi.org/10.21776/ub.ecsofim.2017.004.02.04, Available online at http://ecsofim.ub.ac.id/

[2] Fuad, M. Arif Zainul, dkk. 2016. Pemetaan batimetri sebagai informasi dasar untuk penempatan fish apartment di Perairan Bangsring, Kabupaten Banyuwangi, Jawa Timur. Depik, 5(3): 143-150, Desember 2016, ISSN Cetak: 2089-7790, ISSN Elektronik: 2502-6194, DOI: 10.13170/depik.5.3.5655.

[3] Van Beukering, P., Haider, W., Longland, M., Cesar, H., Sablan, J., Shjegstad, S., Beardmore, B., Liu, Y., Garces, G. O. 2007. The Economic Value of Guam's Coral Reefs. University of Guam Marine Laboratory Technical Report No. 116.

[4] Rujito, H., Utami, M.M.D. and Riskiawan, H.Y., 2018, October. Community Economic Empowerment and Improvement of Meru Betiri National Park Area through Strengthening Community Institutional Capacity. In 1st International Conference on Social Sciences (ICSS 2018). Atlantis Press

[5] Wibowo, N.S., Destarianto, P., Riskiawan, H.Y. Agustianto, K. and Kautsar, S., 2018, May. Development of Low-Cost Autonomous Surface Vehicles (ASV) for Watershed Quality Monitoring. In 2018 6th International Conference on Information and Communication Technology (ICoICT) (pp. 489-494). IEEE. 